
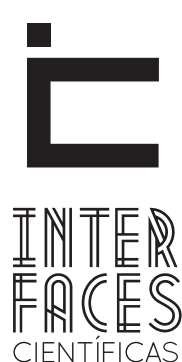

HUMANAS E SOCIAIS

ISSN IMPRESSO 2316-3348

E-ISSN 2316-3801

DOI - 10.17564/2316-3801.2018v7n1p21-32

\title{
A PUBLICIDADE E OS DISCURSOS PLURAIS: OS CORPOS TRANSGÊNEROS
}

\author{
ADVERTISING AND PLURAL DISCOURSE: THE TRANSGENDER BODIES \\ PUBLICIDAD Y DISCURSOS PLURALES: ÓRGANOS TRANSGÉNERO
}

Lícia Frezza Pisa ${ }^{1}$

Ana Carolina Rodrigues Spadin ${ }^{3}$
Victor Vinícius Biazon²

Fábio Eduardo Biazon Abrantes ${ }^{4}$

\section{RESUMO}

Este trabalho pretende apresentar alguns acontecimentos midiáticos em forma de publicidade que colocam em destaque as pessoas transgênero. Por meio da análise de discurso, utilizando-se das noções de dialogismo e verificando o contexto situacional imediato, o contexto institucional e o contexto sociocultural é possível perceber como a mídia, em especial, a publicidade tem se valido de pessoas transgênero para divulgação de suas marcas e, assim, dialogar com os acontecimentos em sociedade, tentar se aproximar de públicos antes marginalizados e divulgar-se como sendo mais plural. $\mathrm{O}$ artigo conclui que, embora haja uma intenção mercadológica e estratégica por trás do uso de pessoas trans, também há - intencionalmente ou não - a representatividade desse público, o interesse por sua trajetória e um trabalho em ressaltar a existência dessas pessoas. Ao mesmo tempo que as campanhas inovam, elas informam às massas a existência de pessoas que não são comuns, mas que devem ser reconhecidas.

\section{PALAVRA-CHAVE}

Comunicação. Dialogismo. Publicidade. Transgênero. 


\section{ABSTRACT}

This paper intends to present some media events in the form of publicity that highlight the transgender people. Through the analysis of discourse, using the notions of dialogism and checking the immediate situational context, the institutional context and the sociocultural context, it is possible to perceive how the media, in particular, advertising has used transgender people to divulge their Brands and thus dialogue with events in society, try to approach previously marginalized publics and publicize as being more plural. The article concludes that although there is a marketing and strategic intention behind the use of trans people, there is also - intentionally or not - there presentativeness of this public, the interest in their trajectory and a work in highlighting the existence of these people. At the same time as the campaigns innovate, they inform the masses of the existence of people who are not common, but who must be recognized.

\section{KEYWORDS}

Communication. Dialogism. Advertising. Transgender.

\section{RESUMEN}

Este trabajo tiene como objetivo presentar algunos eventos de los medios en forma de publicidad que ponen a las personas transgénero en destaque. A través del análisis del discurso, utilizando las nociones dialógicas y comprobando el contexto inmediato de la situación, el contexto institucional y el contexto sociocultural. Es posible ver cómo los medios de comunicación, especialmente la publicidad, hizo uso de las personas trans a divulgar sus marcas y así y así ponerse en diálogo con los acontecimientos de la sociedad, tratan de acercarse al público antes marginados y divulgarse más plural. El artículo concluye que, si bien existe una comercialización y la intención estratégica detrás del uso de las personas trans, también existe - intencionalmente o no - la representatividad de de ese público en su trayecto y un trabajo para señalar la existencia de estas personas. Mientras las campañas buscan innovar, informan a las masas de la existencia de personas que no son comunes, pero deben ser reconocidos.

\section{PALABRAS CLAVE}

Comunicación. Dialogismo. Publicidad. Transgénero. 


\section{INTRODUÇ̄̃̃O}

É possível perceber como a sociedade, de uma maneira geral, tem apresentado uma diversidade de padrões, principalmente relacionados à sexualidade. Dessa forma, fica cada vez mais difícil estabelecer padrões, classificações rígidas e fechadas com relação à identidade de gênero e aos papéis sociais. Essas mudanças com relações aos padrões de heteronormatividade começaram a ser questionados, principalmente, com as lutas feministas na década de 1960 do século XX, procurando um novo lugar para a mulher, para a sexualidade e para a família.

Vários fatores contribuíram para a possibilidade de diversidade que temos hoje. Isso foi possível devido ao crescimento da economia da informação, às descobertas no processo de reprodução humana (controle sobre a gravidez) e a luta das mulheres para ocupar um espaço público em todas as áreas (CASTELLS, 2008, p. 170). Questionando a sexualidade, o movimento feminista buscou novas funções para os papéis de gênero quando não compreendia a heterossexualidade como norma e buscou uma nova definição para a identidade da mulher. Ao questionar o gênero, o feminismo trouxe uma nova expressão, tornando-se uma categoria deliberada em função do homem, por isso a luta para abolir a dicotomia homem/mulher e constituir nova(s) identidade(s) feminina(s) ou não.

Isso deu abertura para os movimentos gays e lésbicos, que lutavam por outras possibilidades de identidades sexuais que iam contra ideologias historicamente impostas, "como a repressão sexual e a heterossexualidade compulsória” (CASTELLS, 2008, p. 256). A rigidez com relação às normas masculinas e femininas era tão categórica que era proibido nos EUA, até o final do século XX, o travestismo masculino, ou seja, nada no vestuário masculino poderia parecer com algo feminino. Os homens deveriam utilizar pelo menos três peças referentes ao seu sexo ou poderiam ser presos (LIPOVETSKY, 2009, p. 154).

Assim, compreendemos que novas estruturas estão surgindo, novos modos de viver, procriar e educar estão aparecendo, pois não há mais um único centro de referência, mas sim uma crescente multiplicidade de expressões culturais e sexuais, por exemplo, que fornecem subsídios para a reconstrução do ser, qual identidade assumir. A diversidade cultural necessita de respostas multiculturais, como a "construção performativa da identidade", em que Butler (2014, p. 74) entende a identidade como uma autonegociação de várias influências para se criar uma representação particular.

Desse modo, é preciso compreender como a publicidade, as marcas estão dialogando com a sociedade em geral, por meio dos interdiscursos, qual imagem pretendem transmitir ao interlocutor e quais intenções estão presentes nas campanhas. Para isso, utilizou-se uma fundamentação teórica sobre comunicação organizacional/empresarial entendida como dialógica ${ }^{5}$, ou seja, aquela que está em constante diálogo com uma parte da sociedade (aquela parte que lhe interessa comunicar) e, portanto, ideológica, pois tem uma intenção ao dizer, está carregada de signos organizados para transmitir uma mensagem, uma imagem e não outra. Nesse processo, utiliza-se a intertextualidade, outros textos presentes na sociedade, para validar, justificar, responder, se posicionar ou intensificar a mensagem. Dessa forma, conta também com o interlocutor para produzir sentido ao que foi transmitido.

De acordo com Pinto (2002, p. 26) a análise de discurso tem como ponto de partida "produtos culturais empíricos produzidos por eventos comunicacionais entendidos como textos" que utiliza a linguagem verbal ou outras semióticas. Encontra-se na superfície dos textos pistas ou marcas deixadas pelos processos sociais de produção de sentidos que o analista vai interpretar e, para isso, é necessário observar três níveis: o contexto situacional imediato, o contexto institucional e o contexto sociocultural mais amplo, no interior dos quais se deu o evento comunicacional. Desse modo, o trabalho visa a apresentar a dialogia presente nos enunciados com transgêneros.

5 Comunicação dialógica será tratada aqui a partir do dialogismo de Bakhtin (2006). 


\section{COMUNICAÇÃO EMPRESARIAL}

A comunicação empresarial, em que as ações de publicidade se inserem, não é utilizada apenas para a simples divulgação de produtos e serviços. Sob a perspectiva da estratégia mercadológica teria, conforme Bueno (2005, p. 14-15) "papel fundamental, tanto na busca de eficácia na interação com os públicos de interesse (stakeholders) como no desenvolvimento de planos e ações que imprimam vantagem competitiva às organizações".

Neste sentido, pode ser inferido que a publicidade das marcas pode se apropriar dos discursos e movimentos sociais para se comunicar de forma direta e interativa com seus públicos. A questão da identidade sexual fica intrínseca nestas ações comunicacionais que utilizam modelos caracterizados ou estereotipados para promoção de discursos de pluralidade sexual.

Para que a empresa esteja atenta a todas as mudanças que podem interferir na imagem da sua marca, o conceito de dialogismo (BAKHTIN, 2006) é útil no sentido de subsidiar a compreensão das mensagens com a escolha de palavras e imagens adequadas ao contexto de produção. Para isso, o discurso publicitário deverá ser encarado enquanto um gênero, pois a linguagem é pensada nas mais variadas esferas sociais e o gênero seria a maneira de se compreender a dialogicidade, a intertextualidade, o ideológico e o estilo nos textos, pois carrega certas características.

O gênero publicitário é reconhecido pelo conjunto de características que o compõe, pois está inserido de forma cultural, social, histórica e temporal na sociedade, refletindo e refratando as mudanças presentes no contexto e, por isso, é considerado "relativamente estável” e que, por isso, reflete as condições de produção apresentando composição, temática e estilo adequado ao que se pretende comunicar. Para Quessada (2003, p. 119), "o poder da publicidade encontra sua origem numa concepção singular e industrial da primeira de todas as mídias: a linguagem". A publicidade "é discurso, linguagem e, portanto, manipula símbolos para fazer a mediação entre objetos e pessoas" (CARVALHO, 2000, p. 12).
Na sociedade dentro dos anúncios, as tribos se organizam. E mais, ganham identidade diferenciada frente aos produtos que consomem. Apontam, assim, para um modelo classificatório, que segue de perto a lógica do sistema de "castas" ou "grupos totêmicos. (ROCHA, 1995, p. 173).

Para Bakhtin (2006), dialogismo, diálogo no sentido amplo do termo, sempre está em relação a alguma coisa, responde a alguma coisa e não é necessariamente linguístico, não é apenas textual, pois extrapola o campo dos sentidos, podendo as relações dialógicas se estabelecerem com imagens, por exemplo, e Quessada (2003) diz que toda imagem é fulminante, atrai a convicção, pode gerar a fé, pois mobiliza a crença. Neste sentido, Soares (2008, on-line) diz que "a publicidade reforça a relação entre produtos e consumidores, podendo até criar novas relações, utilizando modelos culturais existentes, associados aos grupos que são os alvos de suas campanhas".

Dialogismo é um princípio inerente ao funcionamento social da linguagem e, consequentemente, responsável pela produção de sentidos do discurso. 0 dialogismo é concebido na relação entre o eu e o tu e entre o eu e o outro, ambos socialmente organizados. O outro para Bakhtin (2006) tem um papel importante nessa interação, visto que ele valida/constitui o sentido, estabelece a alteridade, produz a compreensão.

As relações dialógicas, ao serem travadas com sentidos e vozes sociais, evidenciam a coexistência de uma pluralidade de manifestações discursivas, que se materializam na noção de heteroglossia, entendida como a interação de múltiplas perspectivas individuais e sociais, representando uma estratificação da linguagem, ou seja, mostra o quanto o indivíduo não é autor soberano das palavras que profere. A forma como expressa-se está sempre impregnada de contextos, estilos e intenções distintas, marcadas pelo meio e pelo tempo em que se vive.

Ao utilizar a dialogia para a compreensão da comunicação publicitária, Pinto (2002) esclarece que a comunicação acontece por meio de uma enunciação como o ato de produção de um texto. Enunciado é o produto cultural produzido, o texto materialmente considerado. Qualquer imagem deve ser considerada 
como um texto, assim como as palavras que o acompanham. As mediações são encaradas como práticas discursivas e sociais de produção de texto em processos institucionais e de consumo e as determinações que o texto sofre por pressão social onde surgiu se fazem por intermediações ideológicas, constituição de identidade social e interesses de grupo, fazendo-se compreender a lógica do dialogismo.

Portanto, a teoria dialógica permitirá compreender, mais aprofundadamente, os anúncios publicitários pelas escolhas do discurso proferido em diálogo com outros discursos sociais que tencionam a produção dos enunciados e constroem, com isso, efeitos de sentido, além de apresentarem a esfera social de circulação em diálogo com outras.

\section{A PLURALIDADE DOS TRANSGÊNEROS}

A palavra transgênero pode ser cada vez mais ouvida por meio da mídia em geral. A questão ganha visibilidade, principalmente, por conta das cirurgias de mudança de sexo. No programa da rede Globo Profissão Repórter foi abordado o tema no dia 18 de novembro de 2014 , onde mostrou a realidade de pessoas que nasceram com um sexo, mas sentem que pertencem de alguma maneira ao sexo oposto e buscam lidar com essa realidade por meio das cirurgias e acompanhamento psicológico.

A realidade é que cada vez mais pessoas não se identificam com o sexo biológico de nascimento e buscam outras maneiras de existirem no mundo. Outros termos são usados atualmente para respaldar os sujeitos que apresentam identidade de gênero diferenciada como, por exemplo, a intersexualidade, quando há aspectos físicos externos ou internos envolvidos na sua identidade sexual. De acordo com Santos (2006), nos últimos vinte anos, autores especialistas afirmaram que a proporção de nascimentos de intersexuais era de 1:10.000 nascimentos. $\mathrm{Na}$ década passada, tal proporção foi atualizada e subiu para 1:2.000 nascimentos ou 1,7\%, podendo hoje ser muito maior. Contudo, tais números são inconclusivos e imprecisos, visto que alguns ainda podem passar a vida toda sem nem mesmo saber que são intersexuais.

Este trabalho dará foco ao termo transgênero e, para o compreendermos, recorreremos aos estudos de sexualidade de Foucault que deram base para feministas como Judith Butler e Joan Scott pesquisarem sobre identidade de gênero e trans.

Foucault (1988), pensando a questão do gênero em sexo e sexualidade, traz o questionamento sobre o sexo ser apenas algo para a reprodução e não algo para o prazer. Assim, o sexo seria parte da natureza e a sexualidade parte do homem, do poder, da dominação e do controle. 0 trabalho de Foucault, apesar de não tratar especificamente de identidades, instaura uma nova fase nas pesquisas sobre identidades sexuais por meio da desconstrução dos discursos historicamente aceitos e localizados até então, compreendendo que a sexualidade é socialmente constituída pelos discursos legitimados que privilegiam a heterossexualidade sobre as outras formas de identidade sexual.

No caso das relações homossexuais - várias outras formas de sexualidade aparecem e a não adequação entre sexo e gênero faz surgir a questão dos transgêneros, pois seus representantes não se enquadram nas classificações fixas dadas pelo binarismo de sexo e gênero.

Judith Butler (2014) também concorda que há um problema com relação à denominação de gênero com sexo, pois o sexo biológico não caracteriza a identidade de gênero: o que é ser homem e o que é ser mulher? A autora analisa a questão pelos estudos de Foucault (1988), mostrando que o gênero é uma relação de poder, em que o sexo, o corpo e a sexualidade organizam a percepção do mundo em determinada cultura. 0 gênero, portanto, cria uma distinção importante para organizar os sexos e a sexualidade e acaba por fundamentar uma lógica heterossexual, pois acaba sempre sendo levada pela ordem "natural" do sexo em que o correto seria uma relação com o sexo oposto, ou seja, ainda mantém os padrões binários de homem/mulher, ativo/passivo, o que ajuda a regular a "família heterossexual monogâmica reprodutiva burguesa” (GROSSI, 1995, on-line). 
0 gênero passa a receber mais atenção sob o questionamento: o que é gênero? Oriundo dos estudos da mulher que lutavam por visibilidade na esfera pública, além de questionar a distinção biológica para justificar a desigualdade entre os sexos, o termo gênero passa a ser utilizado no Brasil por volta de 1980 para determinar o que é ser mulher além da biologia (LOURO, 1997).

A dificuldade encontrada em separar identidade de gênero e sexualidade é que a questão acaba sendo focada na biologia, ou seja, como ciência natural acaba por "naturalizar" o comportamento da sexualidade como provinda de determinado sexo e ambos acabam sendo utilizados como sinônimos no cotidiano. Assim, transtorno de identidade de gênero ${ }^{6}$ seria quando 0 sexo do corpo entra em conflito com o que seria o sexo da mente, o gênero (LEITE JR., 2009).

Dados apresentados pelo documentário “Mistérios da Sexualidade" feito pelo National Geographic afirmam que as estimativas vão desde 1 intersexual a cada 250 nascidos até pouco mais de $1 \%$ da população dos Estados Unidos da América.

Fraser e Lima (2012), ao tratarem da problemática, afirmam haver elementos biológicos (sexo genético, o sexo endócrino e o sexo morfológico que originam a parte física do indivíduo); elementos psicossociais (sexo psicológico e o sexo social, que serão definidos por alguns fatores como a formação educacional, a influência da família e da sociedade, o comportamento do indivíduo e sua afirmação em determinado gênero); e o terceiro elemento que é o aspecto civil ou legal, que é dado pelo aspecto morfológico dos genitais externos do indivíduo.

A concordância entre os sexos genético, endócrino e morfológico de um indivíduo pode ser prejudicada se não houver identificação psicológica dos indivíduos com os sexos em que são classificados (sexo psicológico) e, ainda, a aceitação social dessas pessoas em um ou outro sexo (sexo social). (FRASER; LIMA, 2012, p. 2).

6 Em 1973 John Money junto com Norman Fisk cria o termo "disforia de gênero" para indicar um mal-estar com o próprio gênero (GROSSI, 1995).

7 CONTATO VARIEDADS. Doc. Mistérios da Sexualidade (Completo e Dublado) NatGeo. Disponível em: <https:// www.youtube.com/ watch?v=HbHsMQYNkaU> Acesso em: 12 jan. 2015.
Nesse sentido, seria essa a dificuldade encontrada pelos transgêneros ao dizerem sentir que não pertencem ao corpo em que estão, ou seja, detectando um problema, isso poderá ser tratado com os hormônios deficientes e, possivelmente o sistema nervoso central reagirá se readequando aos novos estímulos, o que poderia trazer mais conforto para a vida dessas pessoas que tentam se enquadrar em certas normalidades de comportamento.

Inclusive Singer (1990, p. 209), quando propõe a androginia como uma nova teoria da sexualidade, questiona que um dos maiores problemas está na rotulação da sexualidade, seja em heterossexual, homossexual, bissexual, pois acredita que as pessoas precisam pertencer a uma dessas categorias e "caso não consigam se aceitar como membros de uma categoria fixa, atribuem-se a tarefa de se modificarem para que possam se enquadrar numa delas" e acabam se submetendo a cirurgias de mudança de sexo, o que tem aparecido recorrentemente na sociedade sob o nome de transgêneros.

\section{OS TRANSGÊNEROS NA PUBLICIDADE}

Para Canedo (2010) a publicidade é a combinação de conteúdos de mensagens e o meio ou canal dentro do qual essa mensagem irá ser transportada e é vista como recurso comum quando se pretende transmitir uma mensagem persuasiva aos sujeitos receptores. Caminhando para a pluralidade nos discursos publicitários, marcas de diversos produtos ao redor do mundo estão utilizando as figuras dos transgêneros em suas ações de comunicação.

A marca Tailandesa de roupa íntima, Wacoal, criou um anúncio ${ }^{8}$ em 2013 apresentando um sutiã e utilizou a figura de uma transexual. Para promover o sutiã mood boost-up o anúncio apresenta a figura sorridente aparentemente de uma garota, feminina, em seu quarto e a transição de imagem mostra alternadamente seus olhos maquiados, seu rosto, partes do seu corpo e seu decote com um pedaço do sutiã a mostra. Numa cena natural em que uma adolescente vê uma revista. Na sequência, a figura que ilustra a peça co-

8 Disponível em https://www.youtube.com/watch?v=p9HNbnhid9U 
meça a retirar a maquiagem, ficando com uma aparência mais masculinizada. Retira-se a blusa e com sensualidade e leveza desabotoa-se o sutiã de costas e ao se virar quando corta para aparecer os seios, percebe-se a figura masculina, que retira a peruca e dá uma piscada de olho para encerrar o comercial.

Percebemos que a peça foi elaborada para causar a impressão de que se trata de uma mulher com seios e durante o processo de demaquilagem, o sujeito vai se despindo de suas formas femininas e delicadas, assumindo seu papel masculino, em corpo de homem.

Em 2014 a marca de cosméticos Redken anuncia Lea T., famosa transgênera brasileira, em sua campanha. A modelo se tornou a primeira transexual a atuar como o rosto de uma empresa de cosméticos. 0 produto anunciado era tintura para cabelo (PARRILLA, 2015). Em 2016, a modelo também fez história ao entrar de bicicleta, apresentando a delegação do Brasil na cerimônia de abertura das Olimpíadas do Rio de Janeiro.

Valentina Sampaio é o nome escolhido pela L'Oréal Paris para a campanha do Dia Internacional da Mulher. No vídeo, a modelo transexual fala sobre "oficialmente" ser seu primeiro dia da mulher e que não queria ganhar flores e sim respeito. A campanha homenageia a todas as mulheres, independente de serem mulheres dentro de um padrão heteronormativo ou transexuais, operadas ou não (FÓRUM, 2016, on-line).

A marca Clean \& Clear, de cosmético, lançou campanha com vídeo intitulado The Real Me - Jazz Jennings: Being Your True Selfg. Jazz relata que sabia desde o primeiro dia que ela realmente era uma menina presa no corpo de um menino. Crescendo como uma menina transgênera, às vezes sentia que tinha que mentir para si para evitar as opiniões dos outros. Agora, tem a coragem de colocar-se lá fora e fazer novos amigos e relata ter sido uma experiência incrível. A Jazz real está feliz ao ser ela e orgulhosa de quem ela é. Além dessa campanha, Jazz foi inspiração para a primeira boneca transgênero, a ser lançada em 2017 em Nova York (REDAÇÃO..., 2017).

9 Disponível em: <https://www.youtube.com/watch?v=vyNZXQ136ol>
Em julho de 2015 a revista Vanity Fair ${ }^{10}$ estampou em sua capa Bruce Jenner, mundialmente famoso pelo reality show que exibia a família Kardashian, após sua transição de gênero, sendo apresentado como "Caitlyn". A capa continha ainda os dizeres Call me Caitlyn. A narrativa conta os medos e dúvidas, amor e coragem, ainda as tensões e traumas envolvidos na transição.

Mais recentemente, foi veiculado um comercial da Nike em que mostra a figura do transexual Chris Moiser, primeiro atleta transgênero a fazer parte da equipe nacional norte-americana masculina de triátlon. A peça ${ }^{11}$ mostra uma rotina de treinamento com passagens de diferentes tipos de atividade física da modalidade, em ciclos, que deixam claro, do amanhecer ao anoitecer, a dura rotina de um atleta olímpico, ao tempo em que as roupas do atleta vão mudando e caracterizando-o com físico masculinizado. 0 diálogo travado entre o narrador e o atleta são questionamentos sobre o atleta saber se seria rápido o bastante para competir contra os homens; forte o bastante; se a equipe o aceitaria; se seria autorizado a competir e sempre a resposta era: "eu não sabia”. Ao final, o narrador questiona: "Deve ter sido difícil para você, você nunca pensou em desistir?” e ele responde: “Sim, mas eu não desisti”.

Podemos compreender, analisando o contexto situacional imediato que há uma maior liberdade midiática na atualidade, pois as marcas hoje podem investir em uma comunicação mais abrangente, surpreendente e polêmica sem ser totalmente rechaçada e rejeitada pelo público. É preciso observar, no entanto, que esse tipo de abordagem nem sempre é bem vista, pois há sempre uma parcela conservadora do público que prefere ver sempre os mesmos padrões estampando as capas de revista e aparecendo nos comerciais da televisão.

Apesar disso, hoje há um público jovem cada vez mais politizado e consciente dos direitos de todos os cidadãos, independentemente de seu gênero ou sexualidade. A aparição de pessoas trans na publicidade

10 Disponível em: <http://www.vanityfair.com/hollywood/2015/06/ caitlyn-jenner-bruce-cover-annie-leibovitz>

11 Disponível em: <https://www.youtube.com/watch?v=_gq8P09XK2Y> 
é, tanto uma evolução, como um passo adiante para mais evolução, uma vez que a publicidade é responsável por levar ao grande público assuntos informativos e inovadores, fazendo com que esse público de massa compreenda, com mensagens curtas e simples, uma nova faceta da sociedade.

No contexto institucional podemos levar em consideração alguns acontecimentos que colaboraram para a visibilidade dos transgêneros. Por volta do século XIX os estudos sobre sexualidade, vista pela vertente médica, começaram a surgir nos países de língua alemã (SAADEH, 2004); em 1973 foi criado o termo disforia de gênero para o transexualismo, incluindo os indivíduos que sofrem algum desconforto com relação ao gênero (SAADEH, 2004); e a partir de 1997 o Conselho Federal de Medicina normatiza cirurgia de mudança de sexo (SAADEH, 2004).

Já no contexto sociocultural mais amplo vemos vários movimentos que produzem discursos contrários aos dominantes, na tentativa de invertê-los ou, pelo menos, ganharem voz. Desse modo, ao pensar a possibilidade de novas formações fora da normalidade heterossexual, devemos lembrar que a classificação da homossexualidade como doença mental foi retirada da lista de doenças da Organização Mundial de Saúde (OMS) em 1990. Até então o sujeito homossexual era tratado como doente e precisava de tratamento para ser curado.

Apesar disso, os gays continuam sofrendo violência de todo o tipo, apesar de ser contra a lei de direitos humanos esse tipo de discriminação, por isso assistimos na mídia em geral vários protestos a favor dos gays e da diversidade. A Lei 3.157 de 27 de dezembro de $2005^{12}$ torna ilícita toda forma de discriminação, prática ou violência de qualquer ordem (psicológica, física, verbal) com relação à orientação sexual de gênero.

Na luta pela igualdade de gênero, podemos lembrar os movimentos feministas do século XX (CASTELLS, 2008) e do grupo ativista Femen ${ }^{13}$, além da sigla LGBTS (lésbicas, gays, bissexuais, transgêneros e simpatizan-

12 Disponível em:<http://www.unisite.ms.gov.br/unisite/controle/ShowFile.php?id=92706>

13 Disponível em: <http://femen.org/> tes) que antes era GLS (gays, lésbicas e simpatizantes), foi modificada como uma medida governamental e de organizações não-governamentais para garantir o direito aos homossexuais, estando, inclusive, em programas como Brasil sem Homofobia (programa de combate à violência e discriminação LGBTS e de promoção da cidadania homossexual) promovido pela Secretaria Especial de Direitos Humanos (JESUS, 2007).

Outro exemplo que mostra a variedade de gêneros ocorreu com o Facebook dos Estados Unidos que passou a disponibilizar 56 opções de preenchimento para o campo gênero como: andrógino, sem-gênero, masculino, feminino, pangênero, transexual, bigênero, não-binário, cis-gênero, neutro etc., mas em 2015 passou a permitir o preenchimento livre no campo gênero sem descrições determinadas (CAPARICA, 2014). Assim, percebemos vários contextos que estão dialogando para a visibilidade dos transgêneros.

\section{CONSIDERAÇÕES FINAIS}

0 padrão heteronormativo sempre esteve presente nas civilizações ditas modernas, mas fica claro que novas estruturas estão surgindo e que as manifestações midiáticas e comerciais se revestirão de novas formas de comunicar-se com seus públicos, sejam os específicos, seja com a sociedade de forma geral, até para que possam se posicionar como marcas que compreendem a diversidade, a pluralidade de gêneros e de corpos.

Neste sentido, respondendo a proposta de compreender como a comunicação das marcas está dialogando com a sociedade em geral por meio dos interdiscursos, foi percebido que os signos inseridos de forma sutil, porém impactantes, mostram que as marcas que buscam atingir um tipo de público diferenciado a partir do uso de pessoas trans, como atores principais de sua publicidade, buscam comunicar-se com toda a sociedade e não somente com os membros cujo "padrão" é salientado na maior parte das campanhas midiáticas. Por meio do choque, da exposição e da aceitação, buscam um tema polêmico, pouco explorado e de certa forma, 
tabu, para prender a atenção do público geral, causar interesse e informar um público leigo e gerar a representatividade do público trans, até então pouco mostrado em campanhas publicitárias.

Não é possível afirmar quais os resultados obtidos em termos de lucratividade para as marcas que usam pessoas trans em sua publicidade, mas é possível afirmar que a lembrança será conquistada se a mensagem foi transmitida, reforçando o dialogismo de Bakhtin.

Possivelmente a enunciação de tais marcas se vale da ideia de Bakhtin quanto à escolha de imagens e palavras, impulsionados dos discursos praticados pela marca, fazendo com que um discurso voltado a pessoas pouco reconhecidas emerja. Mais precisamente, pessoas que a sociedade sabe que existe, mas não comenta, finge que não vê, silencia e as marginaliza como cidadãs. A comunicação de uma empresa ao usar essas pessoas pouco representadas é de uma importância ímpar na comunicação nacional e mundial, pois hoje um gênero pouco entendido pode ser visto mais de perto e, possivelmente, melhor compreendido pela sociedade.

É necessário ressaltar que a maioria das campanhas que abordam os transgêneros são de produtos de beleza e estética. Ou seja, produtos tipicamente femininos, mas que também são procurados por pessoas trans, que se interessam bastante pelo mundo dos cosméticos e prezam pela beleza.

Marcas que captarem e praticarem a tendência de um discurso plural recebem as chances de atingir um público maior, mais variado. Sabendo dialogar como todos eles e em diferentes circunstâncias permitem que possam, mais do que segmentar produtos e expandir suas linhas, darem enfoque ao respeito devido a cada pessoa como cidadã. Deixando claro que não existe um gênero correto, uma sexualidade a qual se possa controlar, possibilita que a onda de conservadorismo seja minimizada com a mensagem clara: pessoas são pessoas, independentemente de seu gênero ou de sua orientação sexual e assim, merecem respeito e representatividade.

Vale ressaltar, no entanto, que não se pode acreditar piamente que as marcas estão realizando um trabalho de cidadania e apenas isso: há um interesse na lucratividade e no reconhecimento pelo pioneirismo em abordar o assunto. A abordagem da transexualidade na publicidade também deve ser vista como uma forma de marcas mais atentas às tendências sociais ganharem vantagem em cima de suas concorrentes, gerando visibilidade a partir da aproximação com públicos com os quais pouco ou nada se comunica.

\section{REFERÊNCIAS}

\section{ÁVALOS, Carlos. La Marca - identidad y estrategia:} recetas para mejorar la relación entre la marca y sus públicos. Buenos Aires, Argentina: La Crujía, 2010.

BAKHTIN, Mikhail. Os gêneros do discurso. São Paulo: Martins Fontes, 1952. In: BAKHTIN, Mikhail. Estética da criação verbal. Tradução Maria Ermantina Galvão G. Pereira. São Paulo: Martins Fontes, 1997.

\section{BAKHTIN, Mikhail. Marxismo e filosofia da}

linguagem. 12.ed. São Paulo: Hucitec, 2006.

\section{BALDISSERA, Rudimar. Comunicação}

organizacional: o treinamento de recursos humanos como rito de passagem. São Leopoldo: Unisinos, 2000.

BUENO, Wilson da Costa. Comunicação empresarial: teoria e prática. Barueri, 2003.

BUENO, Wilson da Costa. A comunicação empresarial estratégica: definindo os contornos de um conceito. Conexão - Comunicação e Cultura, UCS, Caxias do Sul, v.4, n.7, p.11-20, jan-jun. 2005. Disponível em <http://www.ucs.br/etc/revistas/index.php/conexao/ article/viewFile/146/137> Acesso em: 19 mar. 2014.

BUENO, Wilson da Costa. A comunicação empresarial estratégica: definindo os contornos de um conceito.

Conexão - Comunicação e Cultura, UCS, Caxias do Sul, v.4, n.7, p.11-20, jan-jun. 2005. 
BUENO, Wilson da Costa. Comunicação empresarial: políticas e estratégias. São Paulo: Saraiva, 2009.

BUTLER, Judith. Problemas de gênero: feminismo e subversão da identidade. Tradução Renato Aguiar. 7.ed. Rio de Janeiro: Civilização Brasileira, 2014.

CAPARICA, Marcio. Rede social mais popular do mundo está expandindo a identificação dos usuários para além da dicotomia homem/mulher. Viva! Site LADOBI, 21 fev. 2014. Disponível em:< http://www. ladobi.com/2014/02/56-opcoes-genero-facebook/>. Acesso em: 7 maio 2015.

CARDOSO, Onésimo de Oliveira. Comunicação empresarial versus comunicação organizacional: novos desafios teóricos. RAP, Rio de Janeiro, v.40, n.6, p.1123-1144, nov-dez. 2006.

\section{CASTELLS, Manuel. 0 poder da identidade.}

Tradução de Klauss Brandini Gerhardt. 6.ed. São Paulo: Paz e Terra, 2008.

\section{CONTATO VARIEDADS. Doc. Mistérios da} sexualidade (Completo e Dublado) NatGeo. Disponível em: <https:// www.youtube.com/ watch?v=HbHsMQYNkaU>. Acesso em: 12 jan. 2015.

\section{FÓRUM. Modelo trans é escolhida por marca de cosméticos para estrelar campanha do dia internacional da mulher. 2016. Disponível em: <http://www.revistaforum.com.br/2016/03/08/ modelo-trans-e-escolhida-por-marca-de-cosmeticos- para-estrelar-campanha-do-dia-internacional-da- mulher/>. Acesso em: 11 ago. 2016.}

FRASER, Roberta Tourinho Dantas; LIMA, Isabel Maria Sampaio Oliveira. Intersexualidade e direito à identidade: uma discussão sobre o assentamento civil de crianças intersexuadas. 2012. Disponível em: <http://pepsic.bvsalud.org/pdf/rbcdh/v22n3/pt_12. pdf> Acesso em: 10 ago. 2016.
FOUCAULT, Michel. Microfísica do poder. 14.ed. Rio de Janeiro: Graal, 1999.

\section{FOUCAULT, Michel. História da sexualidade: a}

vontade de saber. Rio de Janeiro: Graal, 1988.

GOBÉ, Marc. A emoção das marcas: conectando marcas às pessoas. Tradução de Fulvio Lubisco. Rio de Janeiro: Campus, 2002.

\section{GROSSI, Miriam Pillar. Identidade de gênero e}

sexualidade. 1995. Disponível em: <http://www. observem.com/upload/69a8d4dc71b04390c3096c61 cbc97aed.pdf>. Acesso em: 1 mar. 2015.

JESUS, Beto de. 0 casamento gay pelo mundo: a lei que permite união entre gays já foi aprovada em 17 países. Disponível em: <http://mixbrasil.uol.com. $\mathrm{br} / \mathrm{pride} / \mathrm{pride2005/casamento} \mathrm{mundo/casamento}$ mundo.asp>. Acesso em: 6 maio 2007.

\section{KUNSCH, Margarida M. K. Comunicação integrada} nas organizações moderas: avanços e perspectivas no Brasil. N: Comunicação para o mercado, instituições, mercado, publicidade. São Paulo: EDICON, 1995.

LEITE JR., Jorge. Que nunca chegue o dia que irá nos separar: notas sobre epistémê arcaica, hermafroditas, andróginos, mutilados e suas (des) continuidades modernas. Cadernos Pagu, Campinas, n.33, jul-dez. 2009. Disponível em: <http://www. scielo.br/scielo.php?script=sci_arttextapid=S010483332009000200011 \&lng=pt\&nrm=iso\&tlng=pt>. Acesso em: 25 nov. 2014.

LIPOVETSKY, Gilles. 0 império do efêmero: a moda e o seu destino nas sociedades modernas. São Paulo: Companhia das Letras, 2009.

\section{LOURO, Guacira Lopes. Gênero, sexualidade e}

educação: uma perspectiva pós-estruturalista. 6.ed. Petrópolis/RJ: Editora Vozes, 1997. 
LUPETTI, Marcélia. Gestão estratégica da comunicação mercadológica. São Paulo: Thomson Learning, 2007.

MURARO, Rose Marie; BOFF, Leonardo. Feminino e masculino: uma nova consciência para o encontro das diferenças. Rio de Janeiro: Sextante, 2002.

NOGUEIRA, Pablo. 0 polêmico gene gay. Revista

Galileu, São Paulo: Globo, n.197, p.54-59, dez. 2007.

PARRILLA, Ana Fernández. Lea T, uma mulher de primeira. El Pais. Disponível em: <http://brasil.elpais. com/brasil/2015/09/29/estilo/1443538613_066753. html>. Acesso em: 11 ago. 2016.

PINTO. José Milton. Comunicação e discurso. Introdução à análise de discursos. 2. ed. São Paulo: Hacker editores, 2002.

PROFISSÃO REPÓRTER. Transexuais falam sobre adequação sexual e como encaram a sociedade. G1, 18 nov. 2014. Disponível em: <http://g1.globo.com/ profissao-reporter/noticia/2014/11/transexuaisfalam-sobre-adequacao-sexual-e-como-encaramsociedade.html>. Acesso em: 11 ago. 2016.

\section{QUESSADA, Dominique. 0 poder da publicidade} na sociedade consumida pelas marcas: como a globalização impõe produtos, sonhos e ilusões. Tradução de Joana Angélica D’Avila Melo. São Paulo: Futura, 2003.
ROCHA, Everardo. A sociedade do sonho: comunicação, cultura e consumo. Rio de Janeiro: Mauad, 1995.

ROBERTS, Kevin. Lovemarks: o futuro além das marcas. Tradução Monica Rosemberg. São Paulo: Books do Brasil, 2005.

\section{SAADEH, Alexandre. Transtorno de identidade}

sexual: um estudo psicopatológico de transexualismo masculino e feminino. 2004. $266 f$. Tese (Doutorado em Medicina) - Faculdade de Medicina, Universidade de São Paulo, São Paulo, 2004. Disponível em: <http://www.teses.usp.br/ teses/disponiveis/5/5142/tde-09082005-115642/ptbr.php>. Acesso em: 1 dez. 2014.

SANTOS, Moara de Medeiros Rocha.

Desenvolvimento da identidade de gênero em casos de intersexualidade: contribuições da psicologia. 2006. Disponível em: <http://repositorio.unb.br/ bitstream/10482/6315/1/2006_Moara\%20de\%20 Mederos\%20Rocha\%20Santos.pdf>. Acesso em: 10 ago. 2016.

SOARES, Thereza Maria Zavarese. Sexualidade e publicidade: estratégias discursivas e suas implicações. Revista Vozes em Diálogo (CEH/UERJ), n.2, jul-dez. 2008.

REDAÇÃO VÍRGULA. Primeira boneca transgênero é lançada em feira de brinquedos. Vírgula, 12 fev. 2017. Disponível em: <http://www.virgula.com.br/ comportamento/primeira-boneca-transgenero-elancada-em-feira-de-brinquedos/>. Acesso em: 14 fev 2017 
2 Docente do curso de Administração e Tecnólogos da Faculdade FATECIE e CESUMAR/PR; Doutorando em Comunicação Social pela Universidade Metodista. E-mail: victorbiazon@hotmail.com

3 Mestre em Comunicação Social pela Universidade Metodista de São Paulo. E-mail: aninha_spadin@hotmail.com 